\title{
Ciência médica para cura dos males humanos
}

$\mathrm{Na}$ antiguidade a medicina era exercida inicialmente pelos sacerdotes, mas foi com o "pai da Medicina", Hipócrates, que ela passou a ser transformada numa "ciência", quando ele passou a adotar métodos específicos para a pesquisa dos males humanos. É lógico que a base da pesquisa científica só surgiu cerca de 2000 anos depois com René Descartes ao escrever o Discurso do Método (1637), segundo o qual dizia que só se pode chegar à verdade através da dúvida sistemática e da decomposição do problema em pequenas partes. Assim, podemos dizer que o mais importante é a incessante busca do saber, pois como se diz "Há verdadeiramente duas coisas diferentes: saber e crer que se sabe. A ciência consiste em saber; em crer que se sabe reside a ignorância". Por isso que é admirável a atual formação dos novos médicos, da aprendizagem baseada em problemas que existem nas diversas Faculdades de Medicina do mundo, pois assim temos não só médicos que saibam curar os males humanos, mas também que saibam pensar criticamente e cientificamente possibilitando assim fazer novas descobertas. Desse modo, este novo volume da Revista de Investigação Biomédica 10 artigos científicos de alunos do curso de medicina em suas pesquisas de conclusão de curso. Sendo 2 artigos originais, o primeiro investiga o grau de conhecimento dos estudantes de medicina sobre cuidados paliativos e dor, e o segundo estima a prevalência das hepatites $\mathrm{B}$ e $\mathrm{C}$ em moradores de rua em São Luís-MA.

Os outros artigos são artigos de revisão da literatura, os quais discutiram o uso da testosterona no envelhecimento masculino; a epidemiologia e estratégias de prevenção do câncer de pênis no estado do Maranhão; Câncer de mama em homens; o perfil epidemiológico dos casos de Leishmaniose Tegumentar Americana no Maranhão; o uso de imunoglobulinas na terapêutica da púrpura trombocitopênica imune; a acurácia da ultrassonografia com preparo intestinal no diagnóstico da endometriose profunda; a ultrassonografia das mãos no diagnóstico precoce e seguimento clínico de pacientes com artrite reumatoide e as propriedades farmacológicas de Byrsonima crassifolia.

Desta forma, cada um desses artigos representa o início do cumprimento do juramento de Hipócrates para cada um desses novos profissionais e cientistas da saúde, ou seja, o consagramento da sua vida à serviço da Humanidade.

Silvio Gomes Monteiro

Editor-chefe 